\section{Global Journal of \\ Computer Sciences: \\ Theory and Research}

Volume 8, Issue 1, (2018) 14-23

\author{
Volume 8, Issue 1, (2018) 14-23.
}

www.gjcs.eu

\title{
Modelling and power control of grid connected wind energy system
}

\begin{abstract}
Nadia Ben Si Ali*, Badji Mokhtar-Annaba University, P.O. Box 12 Sidi, Ammar, Annaba 23000, Algeria and Laboratoire de recherche en risques industriels control non destructif et surete de fonctionnement.

Nadia Benalia, Badji Mokhtar-Annaba University, P.O. Box 12 Sidi, Ammar, Annaba 23000, Algeri a.

Nora Zerzouri, Badji Mokhtar-Annaba University, P.O. Box 12 Sidi, Ammar, Annaba 23000, Algeria.
\end{abstract}

\section{Suggested Citation:}

Ali, N. B. S., Benalia, N. \& Zerzouri, N. (2018). Modelling and power control of grid connected wind energy system. Global Journal of Computer Sciences: Theory and Research. 8(1), 14-23.

Received from November 05, 2017; revised from December 12, 2017; accepted from February, $17,2018$. Selection and peer review under responsibility of Prof. Dr. Dogan Ibrahim, Near East University, Cyprus. ${ }^{\circledR} 2018$ SciencePark Research, Organization \& Counseling. All rights reserved.

\begin{abstract}
Wind energy generation has attracted great interests in recent years. Doubly-fed induction generator (DFIG) for wind turbines (WTs) are largely deployed, because variable-speed WTs have many advantages over fixed-speed generation such as increased energy capture, operation at maximum power point, improved efficiency and power quality. This paper presents the operation and vector control of a DFIG system, where the stator is connected directly to a stiff grid and the rotor is connected to the grid through bidirectional back-to-back AC-DCAC converter. The basic operational characteristics, mathematical model of the aerodynamic system and vector control technique, which is used to obtain decoupled control of powers, are investigated using the software Matlab/Simulink.
\end{abstract}

Keywords: Wind turbine, doubly-fed induction generator, active and reactive power controller.

* ADDRESS FOR CORRESPONDENCE: Nadia Ben Si Ali, Laboratoire de recherche en risques industriels control non destructif et surete de fonctionnement and Badji Mokhtar-Annaba University, P.O. Box 12 Sidi, Ammar, Annaba, Algeria. E-mail address: bensialin@yahoo.fr / Tel.: +213 (0) 38872436 
Ali, N. B. S., Benalia, N. \& Zerzouri, N. (2018). Modelling and power control of grid connected wind energy system. Global Journal of Computer Sciences: Theory and Research. 8(1), 14-23.

\section{Introduction}

Wind energy is a renewable source of electricity which is exploited by converting the kinetic energy of moving air into electricity. Doubly-fed induction generators (DFIG) are the most commonly used wind turbine (WT) technology because turbine speed can be adjusted as a function of wind speed in order to maximise the output power (Fletcher \& Yang). It is an attractive and popular option for large WTs (multi-MW). One of the main advantages of adjustable speed generators is improving the system efficiency compared with fixed speed generators. The DFIG WT control system generally consists of two parts: the electrical control on the DFIG and the mechanical control on the WT blade pitch angle. Control of the DFIG is achieved by controlling the variable frequency converter, which includes control of the rotor-side converter (RSC) and control of the grid-side converter (GSC). The objective of the RSC is to govern both the stator-side active and reactive powers independently; while the objective of the GSC is to keep the DC-link voltage constant regardless of the magnitude and direction of the rotor power. The GSC control scheme can also be designed to regulate the reactive power or the stator terminal voltage of the DFIG. The RSC control scheme should be designed in order to regulate the WT speed for maximum wind power capture. Therefore, a suitably designed speed controller is essential to track the optimal WT reference speed for maximum wind power extraction (Barambones, Gonzalez \& De la Sen, 2012). Variable speed operation of WT is necessary to increase power generation efficiency, so this system requires a suitable speed controller in order to track the optimal reference speed of the WT in order to maximise the output power (Bedoud, Lakel, Ali-Rachedi, Lekhchine \& Bahi, 2013; Mechter, Kemih \& Ghanes, 2013).

In this paper, after modelling the DFIG and choosing the appropriate $d-q$ reference frame, the rotor is supplied by an inverter on two levels controlled by pulse width modulation (PWM) technique. The active and reactive powers are controlled using proportional-integral (PI) controllers.

\section{System Description}

The variable-speed WTs consist of stator windings connected directly to the grid and wound rotor windings connected to a power converter. Variable speed generator permits maximum energy capture from a WT. The generator rotor speed is controlled to operate within a variable speed range centred around the generator synchronous speed (Figure 1) (Acakpovi \& Hagen, 2014; Mary, Mathew \& Sreejith, 2010). 


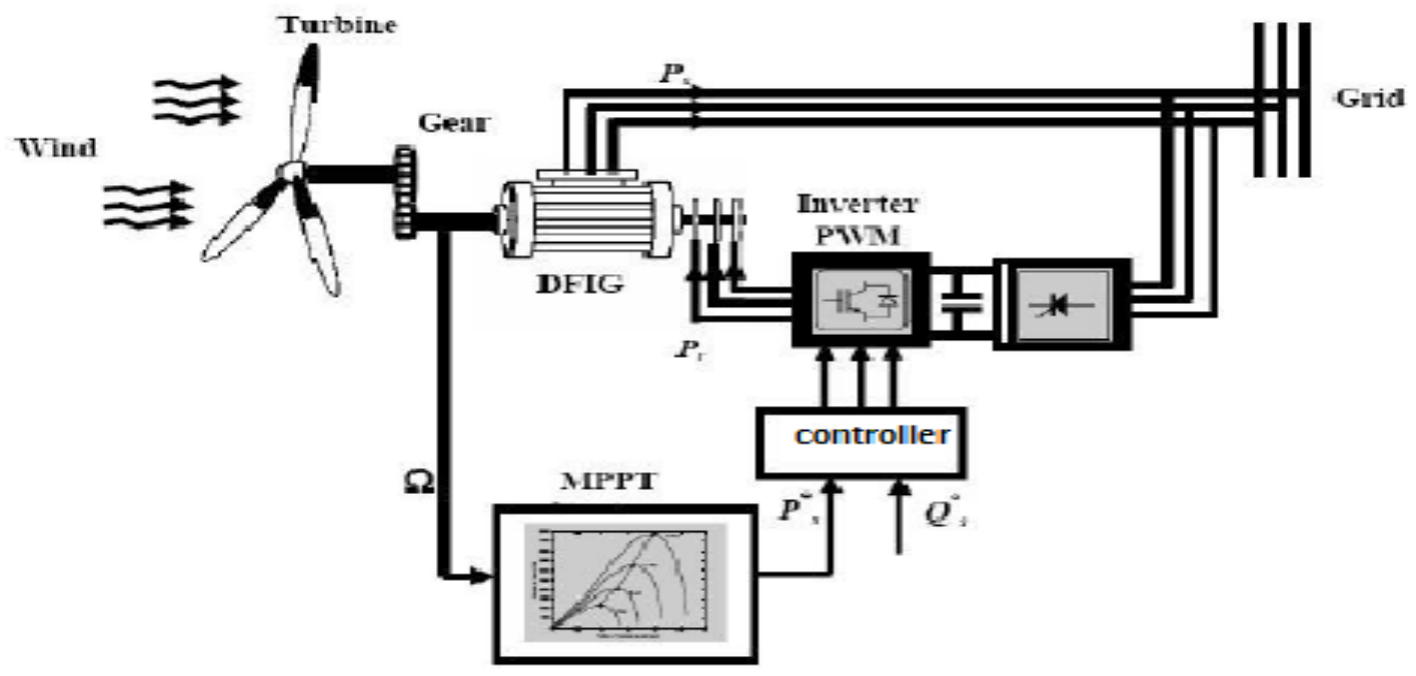

Figure 1. Schematic diagram of DFIG based WT

\section{Doubly-fed Induction Generator Modelling}

The dynamic equation of a three-phase DFIG can be written in a synchronously rotating $d-q$ reference frame as:

$$
\begin{gathered}
\underline{u}_{s}=R_{s} i \underline{-}_{s}+\frac{\mathrm{d}}{\mathrm{dt}} \underline{\psi}_{s}+j \omega_{s} \underline{\psi}_{s} \\
\underline{u}_{r}=R_{r} \underline{i}_{r}+\frac{\mathrm{d}}{\mathrm{dt}} \underline{\psi}_{r}+j\left(\omega_{s}-\omega\right) \underline{\psi}_{r}
\end{gathered}
$$

where

$\underline{u}_{s}=u_{s d}+j u_{s q}, \underline{u}_{r}=u_{r d}+j u_{r q}:$ stator and rotor voltage vectors

$i_{-s}=i_{s d}+j i_{s q}, \underline{i}_{r}=i_{r d}+j i_{r q}:$ stator and rotor current vectors

$\psi_{s}=\psi_{s d}+j \psi_{s q}, \psi_{r}=\psi_{r d}+j \psi_{r q}:$ stator and rotor flux vectors

$L_{s}, L_{r}, L_{m}:$ Stator, rotor and mutual inductances, respectively.

$R_{s}, R_{r}:$ Stator and rotor resistances

$\omega_{s}, \omega$ are the stator angular frequency, the motor angular velocity, respectively.

Stator and rotor flux linkages are:

$$
\begin{aligned}
& \underline{\psi_{s}}=L_{s} \underline{i}_{s}+L_{m} \underline{i}_{r} \\
& \underline{\psi}_{r}=L_{r} \underline{i}_{-r}+L_{m} \underline{i}_{-s}
\end{aligned}
$$

Electromagnetic torque equation is:

$$
T_{\mathrm{em}}=p \frac{L_{m}}{L_{r}}\left(\psi_{r d}{ }^{i} s q-\psi_{r q}{ }^{i} s d\right)
$$




\section{Basic Concepts of wind Turbine}

The aerodynamic model of a WT can be characterised by the well-known $C_{p}=f(\lambda-B)$ curves. $C_{p}$ is the power coefficient, which is a function of both tip speed ratio $\lambda$ and the blade pitch angle 6 . The tip speed ratio $\lambda$ is defined by:

$$
\lambda=\frac{\Omega_{t} R}{v}
$$

Where $R$ is the blade length in meter, $\Omega_{t}$ is the WT rotational speed in rad/second, and $v$ is the wind speed in $\mathrm{m} / \mathrm{s}$. The power coefficient $C_{p}$ gives the fraction of the kinetic energy that is converted into mechanical energy by the WT (Manyonge, Ochieng, Onyango \& Shichikha, 2012).

Mechanical power which is extracted is given by:

$$
P_{m}=\frac{1}{2} \rho A C_{p}(\lambda, \beta) v^{3}
$$


with

$$
C_{p}(\lambda, \beta)=(0.5-0.0167 \cdot(\beta-2)) \cdot \sin \left[\frac{\pi \cdot(\lambda+0.1)}{18.5-0.3(\beta-2)}\right]-0.00184 \cdot(\lambda-3) \cdot(\beta-2)
$$

Where $\rho$ is the air density $\left(\mathrm{kg} \mathrm{m}^{-3}\right)$ and $A$ is the rotor rotational area $\mathrm{m}^{2}$.

Figure 2 shows the $C_{p}=f(\lambda-B)$ curves for some $B$ values. It can be seen that as $B$ increases, $C_{p}$ decreases; thus, reducing the power produced by the WT.

Mechanical torque $T_{\mathrm{m}}$ is the ratio of mechanical power to turbine speed as given by:

$$
\mathrm{T}_{\mathrm{m}}=\frac{\mathrm{P}_{\mathrm{m}}}{\Omega_{\mathrm{t}}}
$$

The mechanical behaviour of the WT is as follows:

$$
J \frac{d \Omega_{m e c}}{d t}+f \Omega_{m e c}=T_{m e c}
$$

With:

$T_{\text {mec }}=T_{g}-T_{e m}$

$T_{g}$ is the torque applied to the DFIG rotor; $T_{e m}$ is the electromagnetic torque developed by the DFIG. $J$ is the total inertia coefficient, $f$ is the friction coefficient.

The gear box is modelled by a simple gain $G$, so:

$$
\begin{gathered}
T_{g}=\frac{T_{m}}{G} \\
\Omega_{\text {mec }}=G \Omega_{t}
\end{gathered}
$$

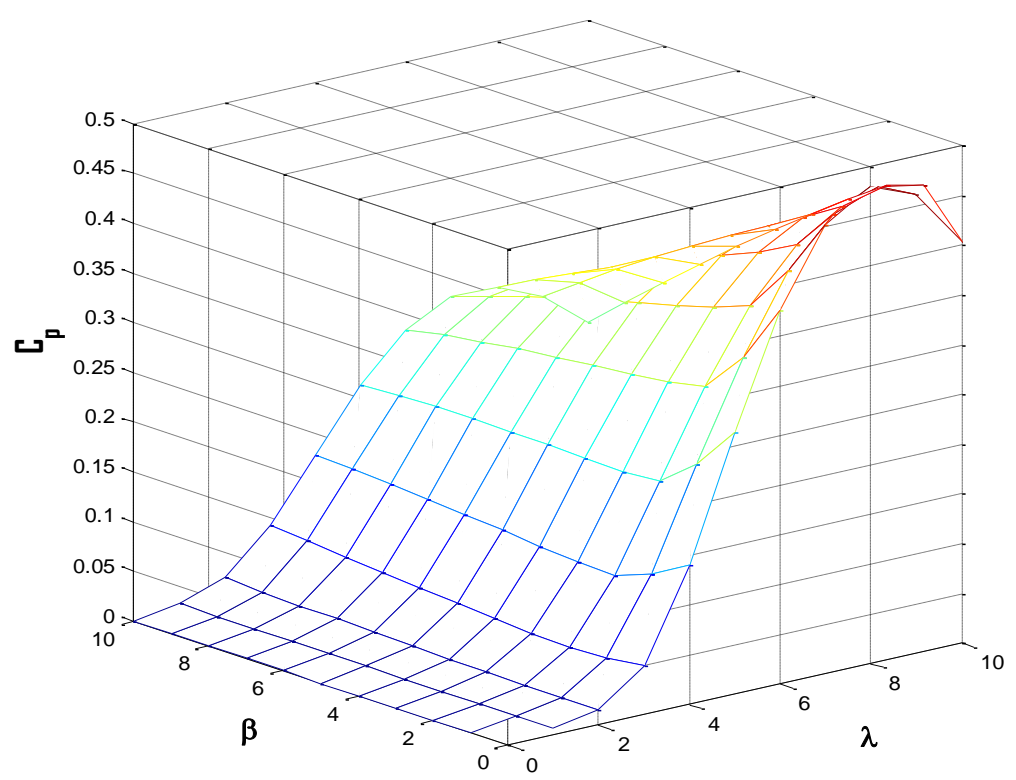

Figure 2. Power coefficient as a function of pitch angle $\boldsymbol{B}$ and tip speed ratio $\lambda$ 
In the maximum power point tracking (MPPT) operation mode without speed controller, the rotor speed of the WT can be adjusted to achieve an optimal tip speed ratio $\lambda_{\text {opt, }}$ which yields the maximum power coefficient $C_{p \max }$, and therefore the maximum power. The value of the $\lambda_{\text {opt }}$ can be calculated from the maximum of the power coefficient curves versus tip speed ratio.

From Eq. (9), mechanical reference speed is obtained by:

$$
\Omega_{\text {mec_ref }}=G \lambda_{\text {cpmax }} \frac{V}{R}
$$

\section{DFIG Vector Control}

WT always operates with different dynamics from minimum wind speed to maximum wind speed. Three wind speeds and two operation modes are possible. Their definitions are as given below (Dingguo \& Zhixin, 2007; Kendouli, Nabti, Abed \& Benalla, 2011):

The cut-in speed is the minimum wind speed at which the WT will generate usable power. The rated speed is the minimum wind speed at which the WT will generate its designated rated power. At very high wind speeds, most WTs are shut down for protection purposes. It's the cut out speed.

\section{Vector Control Strategy}

In order to achieve a decoupled control of active and reactive powers, stator flux oriented vector control scheme is used. In this case, the frequency and amplitude of the stator for grid voltage is assumed constant (stable grid). The strong coupling between the fluxes and currents makes controlling of the DFIG particularly difficult. So, vector control also called oriented flux control is used. The $d-q$ reference frame is linked to the rotating field. The stator flux is oriented along the $d$ axis.

The above assumptions lead to the following:

$$
\left\{\begin{array}{c}
u_{s d}=0, \mathrm{u}_{\mathrm{sq}}=\mathrm{V}_{\mathrm{s}}=\omega_{\mathrm{s}} \rho_{\mathrm{s}} \\
\phi_{s d}=\phi_{s}, \phi_{s q}=0
\end{array}\right.
$$

Using the vector control, the active and reactive powers of the DFIG can be expressed as follows:

$$
\left\{\begin{array}{c}
P_{s}=-V_{s} \frac{L_{m}}{L_{s}} I_{r q} \\
Q_{s}=V_{s} \frac{\phi_{s}}{L_{s}}-V_{s} \frac{L_{m}}{L_{s}} I_{r d} \\
P_{s}=S V_{s} \frac{L_{m}}{L_{s}} I_{r q} \\
P_{s}=S V_{s} \frac{L_{m}}{L_{s}} I_{r d}
\end{array}\right.
$$




\section{Rotor Side Converter Control}

The control principle of the RSC allows the control of active and reactive powers and the extraction of maximum wind power. The power control loops generate the reference values of the $d$ - and $q$-axes rotor currents for the current control loops (Figure 3 ).

Each control loop has a cascaded structure: a fast inner current control loop, controlling the rotor current $I_{\text {dqr }}$ combined with an outer slower control loop for active and reactive powers, respectively. An MPPTprovides the reference signal $P_{\text {Grid, ref }}$ for the active power, while the reactive power $Q_{\text {Grid, ref }}$ is generally set to 0 . The slower power control loop has as an output the reference rotor current signal $I_{\mathrm{dq}}$, Rotor, ref, which is further used by the fast inner current control loop. Finally, two control signals for the rotor voltage vector $v_{\mathrm{dr}}$ and $v_{\mathrm{gr}}$ are generated, which are sent to the PWM-controlled power converter (Gail, Hansen \& Hartkopf).

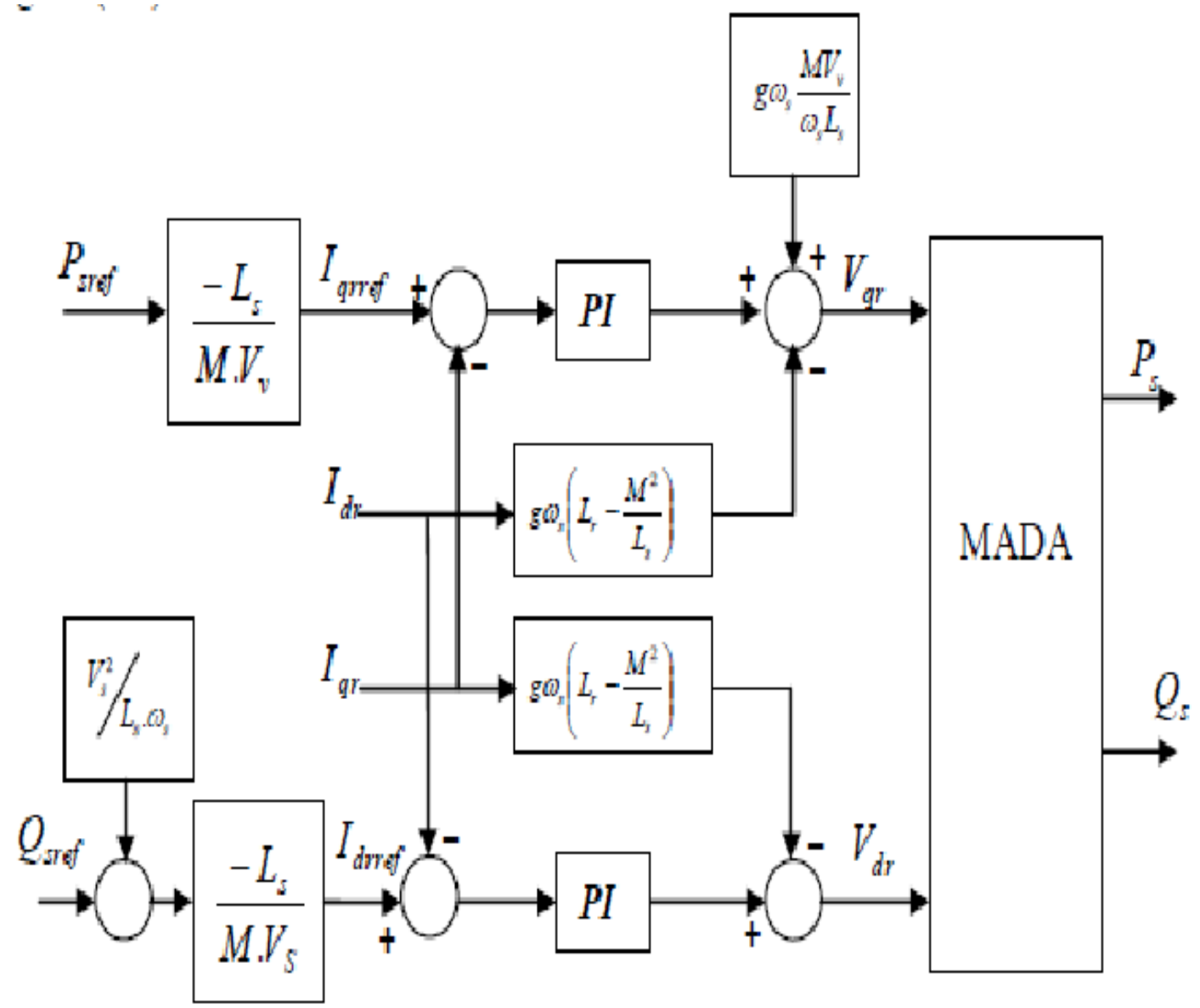

Figure 3. Active and reactive power control of the DFIG

\section{Simulation Results}

Simulation studies are carried out in Matlab/Simulink. The simulation parameters of the DFIG WT are given in Table 1 of the Appendix A. Our aim is to make the stator active and reactive power control track its reference variations. The studied system has been tested for a step change of active reference power and reactive reference power as shown in Figure 4 . The unity power factor 
Ali, N. B. S., Benalia, N. \& Zerzouri, N. (2018). Modelling and power control of grid connected wind energy system. Global Journal of Computer Sciences: Theory and Research. 8(1), 14-23.

is obtained by setting $Q f-r e f=0$. Figure 5 illustrates stator and rotor voltages and currents of the DFIG WT for the simulation test designed.

Figures 6 and 7 show simulation results when controlling the DFIG with a PWM RSC.
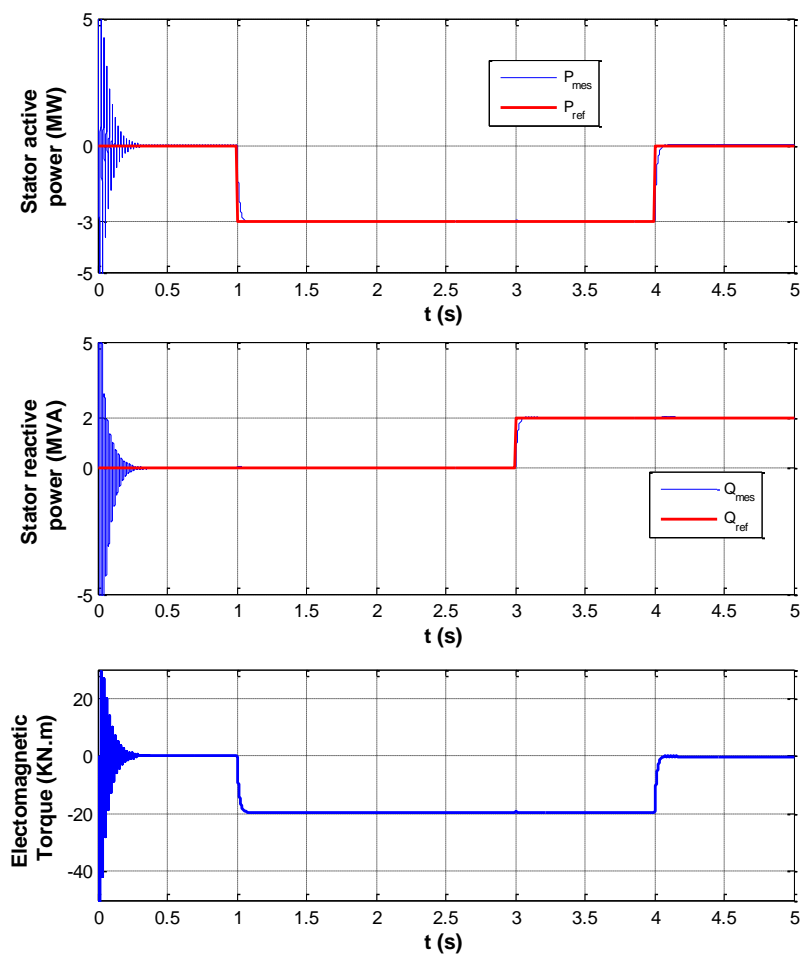

Figure 4. Stator active and reactive powers of the DFIG 
Ali, N. B. S., Benalia, N. \& Zerzouri, N. (2018). Modelling and power control of grid connected wind energy system. Global Journal of Computer Sciences: Theory and Research. 8(1), 14-23.
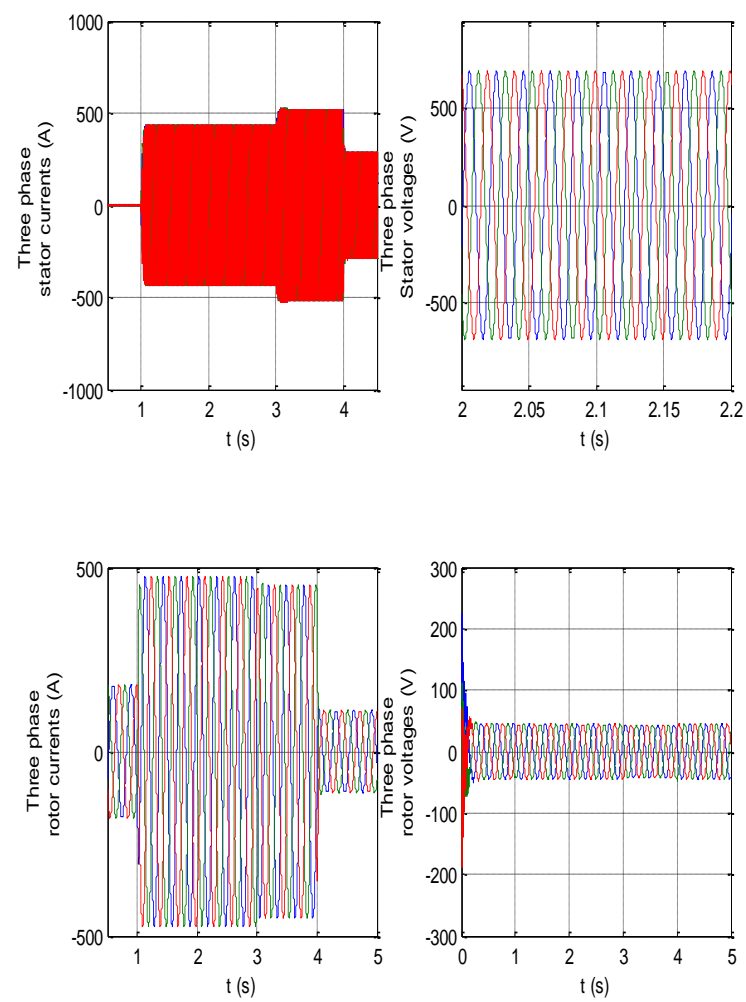

Figure 5. Three phase stator and rotor voltages and currents
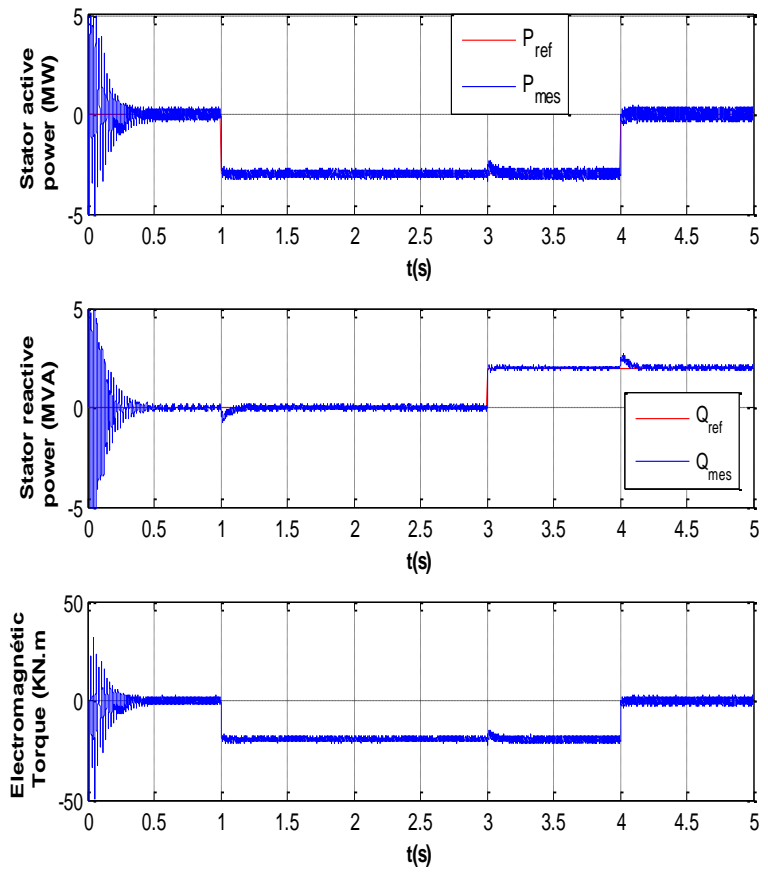

Figure 6. Stator active and reactive powers with PWM RSC control 

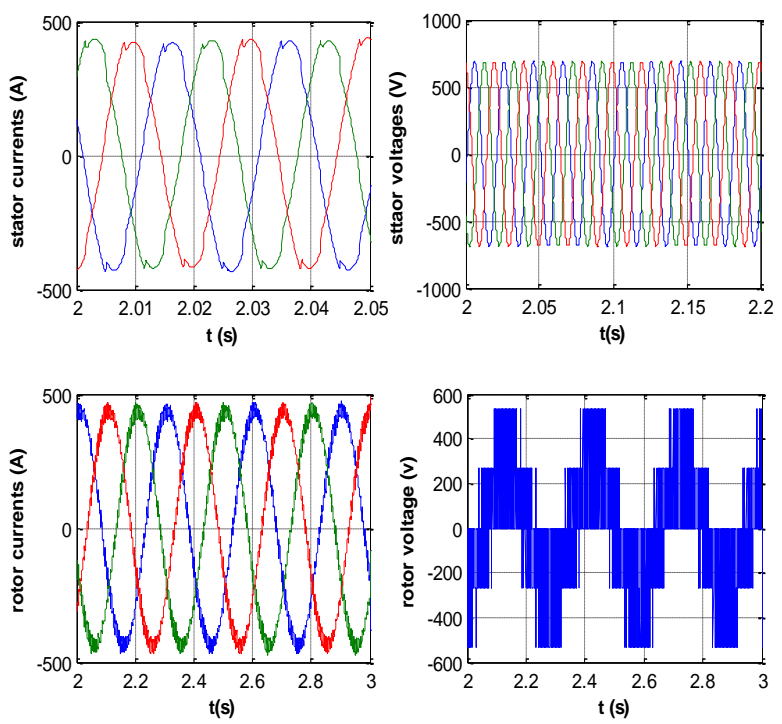

Figure 7. Three phase stator and rotor voltages and currents

\section{Conclusion}

This paper analysed the mathematical model of DFIG and vector control strategy based on the stator flux orientation, established a dual-loop PI control that can realise the active and reactive powers decoupled control by adjustment of $d, q$ components of rotor current, respectively. The MPPT under speed control mode and power control mode is discussed. The simulation results show the dual-loop vector control strategy of double-fed wind power generation system is correct and effective, and the power control mode is more suitable for practical application for its better stability than the speed control mode.

\section{Nomenclature}

DFIG WT parameters and list of symbols are:

\begin{tabular}{ll}
\hline Rated power & $1.5 \mathrm{MW}$ \\
Rotor diameter & $35.25 \mathrm{~m}$ \\
Gearbox ratio & 90 \\
Friction coefficient: & 0.0024 \\
Moment of inertia: $J$ & 1,000 \\
Stator voltage/Frequency & $690 \mathrm{~V} / 50 \mathrm{~Hz}$ \\
$R s / R r(\Omega)$ & $0.012 / 0.021$ \\
$L m / L s / L r(H)$ & $0.0135 / 0.0137 / 0.013675$ \\
$R f(H) / L f(H) / C(F)$ & $0.000002 / 0.005 / 0.044$ \\
Number of pole pairs: $p$ & 2 \\
$V d c$ ref & $2,000 \mathrm{~V}$ \\
$P_{s,} Q_{s}$ & Stator active and reactive powers \\
$P_{r}, Q_{r}$ & Rotor active and reactive powers \\
$V_{s d, q}$ & Stator $d-q$ frame voltage \\
$V_{r d, q}$ & Rotor $d-q$ frame voltage \\
$I_{s d, q}$ & Stator $d-q$ frame current \\
$I_{r d, q}$ & Rotor $d-q$ frame current
\end{tabular}


Ali, N. B. S., Benalia, N. \& Zerzouri, N. (2018). Modelling and power control of grid connected wind energy system. Global Journal of Computer Sciences: Theory and Research. 8(1), 14-23.

\begin{tabular}{ll}
$\phi_{s d, q}$ & Stator $d-q$ frame flux \\
$\phi_{r d, q}$ & Rotor $d-q$ frame flux \\
$R_{s,} L_{s}, R_{r}, L_{r}$ & Stator and rotor resistances \\
$L_{m}$ & and inductances \\
$\omega_{s,} \omega_{r}$ & Mutual inductance \\
\hline
\end{tabular}

\section{References}

Acakpovi, A. \& Hagen, E. B. (2014). A wind turbine system model using a doubly-fed induction generator (DFIG). International Journal of Computer Applications, 90(15), 6-11.

Barambones, O., Gonzalez, J. M. \& De la Sen, M. (2012). Robust speed control for a variable speed wind turbine. International Journal of Innovative Computing, Information and Control, 8(11), 7627-7640.

Bedoud, K., Lakel, R., Ali-Rachedi, M., Lekhchine, S. \& Bahi, T. (2013, aout 26-30). Modelisation d'une chaine de conversion d'energie eolienne Basee sur une machine asynchrone a double alimentation. 21eme Congres Francais de Mecanique Bordeaux.

Dingguo, W. \& Zhixin, W. (2007). Modeling and design of control system for variable speed wind turbine in all operating region. International Journal of Systems Applications, Engineering \& Development, 1(3), 27-38.

Fletcher, D. \& Yang, J. Introduction to doubly-fed induction generator for wind power applications. In Paths to sustainable energy. Glasgow, UK: University of Strathclyde.

Gail, G., Hansen, A. D. \& Hartkopf, T. Controller design and analysis of a variable speed wind turbine with doublyfed induction generator. Department of Renewable Energies, Institute for Electrical Power System, University of Technology Darmstadt.

Kendouli, F., Nabti, K., Abed, K. \& Benalla, H. (2011). Modelisation, simulation et controle d'une turbine eolienne a vitesse variable basee sur la generatrice asynchrone a double alimentation. Revue des Energies Renouvelables, 14(1), 109-120.

Manyonge, A. W., Ochieng, R. M., Onyango, F. N. \& Shichikha, J. M. (2012). Mathematical modelling of wind turbine in a wind energy conversion system: Power coefficient analysis. Applied Mathematical Sciences, 6(91), 4527-4536.

Mary, D., Mathew, S. \& Sreejith, K. (2010). Modelling and simulation of grid connected wind energy system. International Journal of Soft Computing and Engineering, 2(5), 77-89.

Mechter, A., Kemih, K. \& Ghanes, M. (2013). Power control of the wind turbine for low wind speed. Proceedings of the first International Conference on Nanoelectronics, Communications and Renewable Energy. 